International Journal of

Health, Medicine and

Nursing Practice

(IHMNN)

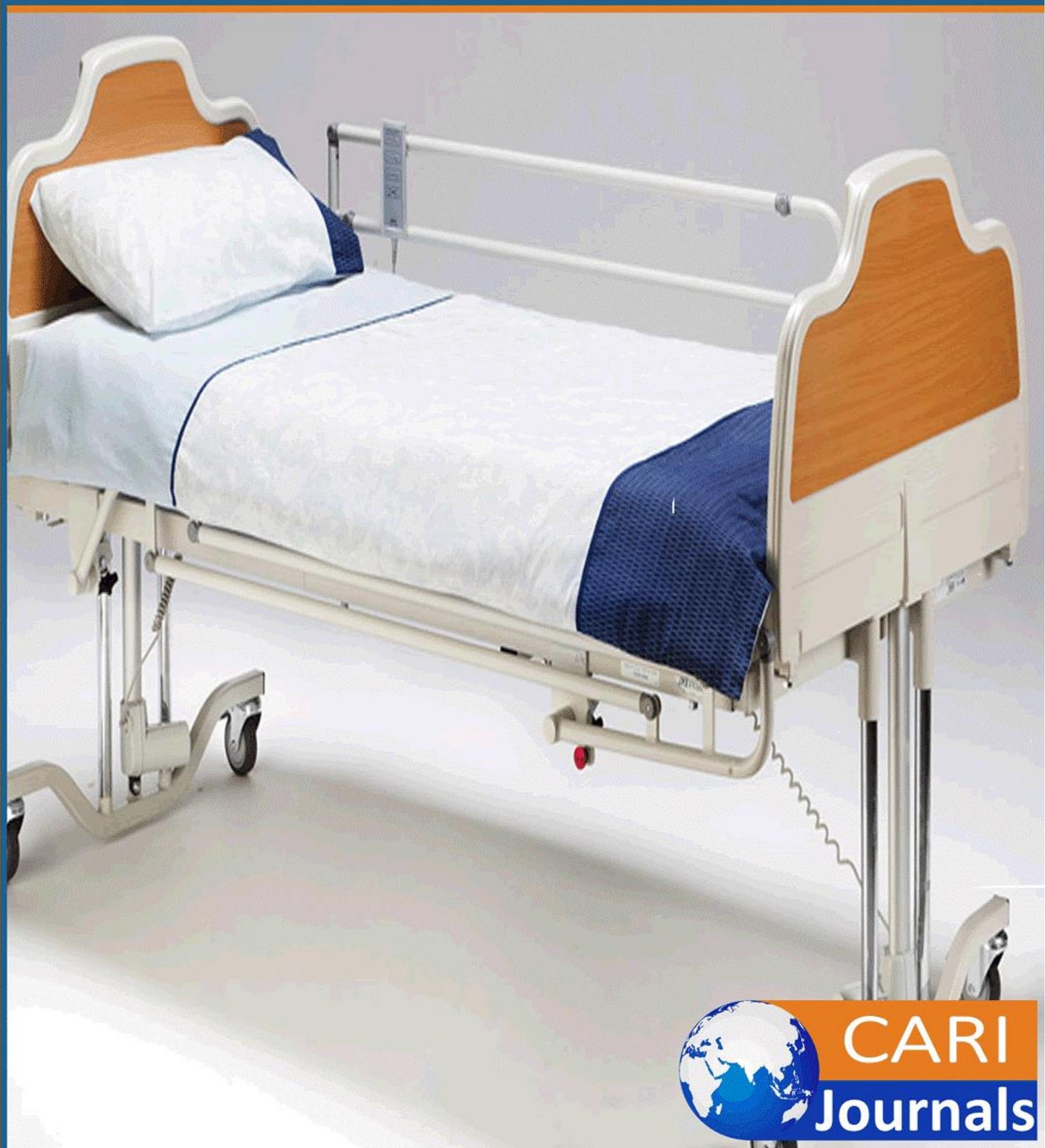




\title{
Social-Cultural Determinants of Male Partner Involvement in An tenatal Care at Anti-Stock - Theft - Unit Kenya
}

\author{
${ }^{1 *}$ Wanjiku Lucy \\ MScN Student: Jomo Kenyatta University of Agriculture and Technology, Kenya. \\ Corresponding Author's Email Email: 1wanjiku2012@gmail.com \\ ${ }^{2}$ Dr. Mutisya Albanus, Kyalo \\ Senior lecturer- Jomo Kenyatta University of Agriculture and Technology, Kenya. \\ Corresponding Author's Email Email: amutisya@jkuat.ac,ke \\ ${ }^{3}$ Kariuki Wanja Dainah \\ Lecturer- Jomo Kenyatta University of Agriculture and Technology, Kenya. \\ Corresponding Author's Email: dwkariuki@jkuat.ac.ke
}

\begin{abstract}
Purpose: Male involvement in antenatal care is a problem identified by different researchers and experienced globally. It is a key component in the optimization of maternal health and universal maternal health achievement. Few men engage in care in developing countries. The current study sought to identify Social-cultural Determinants of Male Partner Involvement in Antenatal Care.
\end{abstract}

Methodology: Descriptive cross-sectional research design. Simple random sampling was used to sample 334 subjects from 2582 population. Data was gathered using self- administered questionnaires, edited, coded, and organized with help of statistical Package for Social Sciences (SPSS), then analysed using descriptive and inferential statistics. Hypothesis was tested using Chi square tests of independence and information presented using tables and percentages.

Results: Majority (92.8\%) of subjects were affiliated to religion. On cross tabulation, (100\%) of participants who accompanied the partners during the first ANC visit disagreed that religion impairs male partner participating in antenatal care unlike $(100 \%)$ of those who did not. Chi squire tests of independence was $(\mathrm{p}=0.047)$. Majority $(77.2 \%)$ of the respondents preferred traditional birth attendants for partner's antenatal care compared to $15.6 \%$ for health care workers. On cross tabulation, (93.3\%) of the participants who accompanied partners during the first ANC visit indicated that they preferred health care providers to traditional birth attendants while $81.8 \%$ of those who did not accompany the partners indicated preference for traditional birth attendants and $9.1 \%$ preferred care workers. Chi squire tests of (independence $(\mathrm{p}=0.001)$.

Unique contribution to theory, practice and policy: Male partner involvement in maternal health is desirable at the study area and there is need of social supports such as informational, appraisal, instrumental and emotional supports to enhance physical, psychological well-being, social integration and social ties. Researcher highlights the need to address religion and traditional birth attendants' reliance which were found significant and established as barriers of male partner participating in ANC and causes of low ANC attendances among pregnant women. Further, policy change is advocated so that the government can pass laws which oblige men to be responsible for pregnant partners by accompanying them to ANC, knowing ANC 
International Journal of Health, Medicine and Nursing Practice ISSN 2710-1150 (Online)

Vol. 3, Issue No.1, pp 1 - 15, 2021

schedules, discussing interventions, supporting the ANC fees if applicable, and knowing what happens at the ANC during the current pregnancy.

Key words: Antenatal Care, Determinants, involvement, Social-cultural

\subsection{INTRODUCTION}

Antenatal care is provision of essential services to pregnant women to ensure safe pregnancy, skilled delivery and family planning preparation. It is one of the pillars of safe motherhood and a determinant of maternal health (Roth, \& Mbizvo, 2010 p.10-21). It involves healthy life styles promotion, treatment of health problems and regular check-ups to improve health that benefit mother, fetus and the male partner (Kakaire et al., 2011).

Prenatal visits are four starting when the woman knows she is pregnant or at 16 weeks gestation. The second is between 16 to 28 weeks while the third visit is between 28 to 32 weeks. The fourth visit is expected at gestation of 32 to 40 weeks (Clement, \& Sikorski 2016). Currently this schedule is under review (Abbas et al, 2012) and recent evidence suggests that ongoing focused antenatal care (FANC), developed in 1990s advocating for four visits, is associated with more perinatal deaths than the eight scheduled visits (Matiang'i et al., 2013, p.117-122).

According to Dhange et al., (2013), assessment of maternal needs and family dynamics is done at the initial visit and with the aid of a special booking checklist, the women are classified as either normal risk or high-risk Teachings on management of lifestyle changes and discussions with caregiver are made during regular check-ups (Caldwell, 2013). Routine prenatal visits play part in reducing maternal and neonatal deaths, miscarriages, birth defects, low birth weight and other preventable health issues (Durban, 2014). Health assessment consist of woman's history, head to toe examination, checking blood pressure, measuring height, weight, doppler fetal heart rate monitoring and ultra sound sonography (Namasivayam et al., 2012). Mothers' antenatal profile is done on first visit and feed-back given (Kululanga, et al., 2012).

Birth preparedness is assessed based on the number of arrangements like birth place, means of transport, funds, birth companion, items for a new born, clean safe birth and complication readiness (Mills, 2010). Male partner involvement in ANC is scored using variables (Nwakwuo et al., 2013) such as the man accompanying the wife to ANC, knowing the ANC schedules, discussing the ANC interventions with the female partner, supporting the ANC fees if applicable, and knowing what happens at the ANC during the current pregnancy. Scores between $0-3$ is considered weak while scores of 4 and above is considered as high male involvement (Onyango, 2010).

According to Aluisio, (2011), male ANC involvement benefits have been acknowledged, but there continues to be challenges in creating space in maternal programs that include and engage men. Male partner involvement leads to supporting spouses to utilize ANC services early there by impacting positively maternal health (USAID, 2010). Efforts to improve women's health during pregnancy and delivery began in developing countries after Safe Motherhood Conference held in Nairobi Kenya in 1987. However related studies show little reduction of maternal issues which is attributed to failure to incorporate men (Matiang'i et al., 2013, p: 117 $-1)$

There is little evidence to prove decline in maternal complications during pregnancy in African countries which is attributed to few men attending appointments with their pregnant partners (Azuh et al., 2015). Male partner non- involvement in antenatal care is a problem experienced globally and needs to be addressed as a crucial component in optimization of maternal health 
International Journal of Health, Medicine and Nursing Practice ISSN 2710-1150 (Online)

Vol. 3, Issue No.1, pp 1 - 15, 2021

www.carijournals.org

and achievement of the third Universal Sustainable Development Goal (United Nations, 2015). 22) It is in this regard therefore that deliberate and active male participation is needed to ensure better maternal health (Kato-Wallace et al., 2014).

\subsection{Statement of the Problem}

Global statistics shows low male partner involvement in ANC (Plantin, 2011). Additionally, traditionally men have not been involved in the reproductive health care and therefore, there has been a low and declining rate of male involvement in the antenatal clinic in the country. National program report by NASCOP (2014), showed male partner involvement in the antenatal clinic by region was: Central 3\%, Western 5.3\%, Nairobi 5.2\%, Rift valley $4.6 \%$, Eastern 6\%, Coast 3.4\%, Nyanza 6.4\% and North Eastern 2\% an average of 5.1\%.

Records review in selected Health facilities (Pumwani maternity Hospital, Nakuru county Hospital and Gilgil Sub-County Hospital) showed few male partner clinic attendances and were mostly invited for prevention of mother to child transmission testing and management. However, records at ASTU as shown in table 1 below few pregnant women attended antenatal clinic with no male partner's participation which prompted the researcher to explore the reasons as to why.

Table 1: ANC attendances Dec.2017 to May 2018

\begin{tabular}{|c|c|c|c|c|c|}
\hline Months & $\begin{array}{l}\text { First } \\
\text { visit }\end{array}$ & Revisit & Total & $\begin{array}{ll}\text { clients } & \text { with } \\
\text { partners } & \end{array}$ & $\begin{array}{l}\text { PMTCT with } \\
\text { Partners }\end{array}$ \\
\hline Dec. 2017 & 16 & 18 & 34 & 0 & 0 \\
\hline Jan.2018 & 22 & 17 & 39 & 0 & 0 \\
\hline Feb.2018 & 11 & 20 & 31 & 0 & 0 \\
\hline March2018 & 15 & 23 & 38 & 0 & 0 \\
\hline April & 15 & 19 & 34 & 0 & 0 \\
\hline May & 35 & 26 & 61 & 0 & 0 \\
\hline Total & 114 & 123 & 237 & $\mathbf{0}$ & $\mathbf{0}$ \\
\hline \multicolumn{2}{|c|}{ Grand total ANC Visits } & 237 & & $\mathbf{0}$ & $\mathbf{0}$ \\
\hline
\end{tabular}

Source; ASTU facility ANC, PMTCT Registers

\subsection{LITRATURE REVIEW}

\subsection{Communication}

The pre-existing level of communication between the couple about antenatal health issues influences the acceptability of prenatal clinic visits by the male partner (San Sebastian, 2011). Poor communication between men and female partners is associated with poor male involvement in partners' prenatal care. On the other hand, good couple communication is associated with high seropositive status disclosure and support between partners (Mohlala , 2011). Study focusing on communication and involvement of men in antenatal care and readiness to provide support to female partners, revealed that male partner support is core to prevention of mother to child transmission (PMTCT) in such as use of antiretroviral drugs prophylaxis and choice of baby's feeding options (Elizabeth Glaser, 2010). Study done in Malawi indicates that there is low male partner involvement in PMTCT services in many SubSaharan countries (Montgomery et al., 2016) resulting from lack of communication about care seeking intentions. Moreover, men keep to themselves waiting for the woman to make a request to be accompanied to the proposed care visit (Mohlala,2011). Research results suggests that 
International Journal of Health, Medicine and Nursing Practice ISSN 2710-1150 (Online)

Vol. 3, Issue No.1, pp 1 - 15, 2021

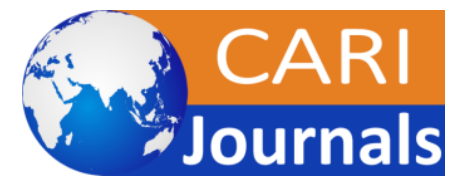

WWW.carijournals.org

information, ducation, and communication (IEC) through media advertisements, and motivation talks on male involvement in ANC would promote interest in men and decision to participate in care (Namasivayam et al., 2012).

\subsection{Culture}

Researchers has found that decision making and care seeking is a process that requires couples understanding of reproductive needs of a pregnant woman but has been restricted by culture and individual disposition, which seemingly renders men to limited ANC visits (Montgomery et al., 2016). Men's participation in ANC is affected by cultural barriers centered in tribal beliefs and traditional gender roles. The barriers identified include the belief that pregnancy is a woman's affair and services are designed and reserved for women and so men are embarrassed to find themselves in such "female" places. Cultural standards are identified as barriers in the community when man is seen accompanying the pregnant woman to antenatal clinic (Abbas et al, 2012).Further men are said to be jealous, dominated by the wife or considered weaklings by the peers (Abbas et al., 2012). However, according to culture, certain women too do not like to be seen with a male partner attending the ANC services (Byamugisha et al., 2010).

Further research has shown that some male partners strictly adhere to culture and do not allow the partner to attend ANC but to consult with traditional authorities from a given village or location for ancestral blessings and care. Again, the elders decide the traditional birth attendant to consult about fetus condition failure to which the couple is considered as outcasts by the community hence denying male partner involvement in partner's pregnancy (Kululanga et al., 2012).

Cultural practices limit the availability of resources to pregnant women, resulting in adverse health consequences, and influence prenatal health by not allowing room for effective health promotion efforts, access to available quality health and understanding societal change and population processes such as current rates of morbidity, mortality and survival among pregnant women. Factors such as neighborhoods has continued to play a role in shaping perceptions and responses to health problems and impact poor health on lives and well-being needed in pregnancy where men who accompany wives for prenatal care are subjected to mockery (Abbas et al., 2012).

Males' inconsistent participation in ANC is increased by not living together with the pregnant woman, family members living with male partners and the wife or family members influencing male partner's decision not to get involved in partner's welfare. This results to failure to make plans for emergency situations during pregnancy (Azuah et al., 2015). Polygamy, a common marital practice in many African countries, is deeply engrained in culture, where multiple partners are considered part of masculinity (Bove et Al., 2014). Many studies have shown that in polygamous unions, senior wives suffer from more psychological disorders and economic problems to meet pregnancy needs, as compared to counterparts in monogamous marriages (Dudgeon, 2014).

\subsection{Traditional birth attendants' reliance}

Cultural values include traditional beliefs which make some couples to trust traditional medicine compared to modern medicine and skilled health care. These values and beliefs are reasons for reliance on traditional birth attendants, who are considered more secretive and friendly than professional healthcare workers (Azuah et al., 2015). In certain regions, research has identified a general conceptualization associated with pregnancy and poses a significant 
obstacle to male partner involvement in antenatal care since in these areas only a traditional female birth attendant or a traditional healer should attend to antenatal needs, conduct a delivery or escort a pregnant woman to a health facility in case of pregnancy complications (Clement et al, 2016).

\subsection{Religion}

Male partner may feel uncomfortable talking about sexual and pregnancy related concerns with the partner or with health educators due to religion that prevent individuals from seeking reproductive health information and services ( Kululanga et al., 2012). In addition, some men believe that engaging in prenatal health matters is contrary to the teaching of religion. Men surveyed in Bangladesh, Egypt, and Pakistan cited religion as a reason they would not disclose to partners' health issues or intentions about participation in ANC with the wife. Others who go against the rule seek religious leaders for spiritual cleansing after the visit (Kululanga et al., 2012).

\subsection{Theoretical review}

\subsubsection{Social network Theory}

The research is based on social network theory by John Arundel Barnes, who used social network concept and described patterns of social relationships (Speizer et al., 2010), which relates to social support as one of the important functions of social relationships and serves as a "protective" factor which assists in overcoming effects of stress on health (Elizabeth Glaser, 2010).

\subsubsection{Core Assumptions}

Social network and social support help a person cope with stressful events and enhances physical psychological well-being and health behavior closely related to social integration which refers to existence of social ties (Dudgeon, 2014). Informational support, appraisal support, instrumental support and emotional support are distinguished types of social supports.

\subsubsection{Theory Application to the study}

The theory is useful in social support and is ideal for understanding the interpersonal influences of male partner involvement in Antenatal care of the pregnant partner. The theory is used for promoting health during pregnancy and alter social cultural determinants and influence male partner involvement in prenatal care and play part to support behavior change. The theory is relevant especially when considering partnership patterns, social behavior, positive relationships and further appreciates that pregnancy directly involves two people involved in social ties. It focuses on benefits associated with male partner involvement in antenatal care and importance of provision of various necessary supports to the pregnant partner as social influence needed for the women's wellbeing thus alleviating effects of stress associated with non- accompaniment by the male partner to antenatal clinic (Stapleton et al., 2012).

Social networking and social support indicate that, male partner participation in ANC increases spousal discussion about sexual risks and behavior change (Farquhar et al., 2014). This becomes critical in discordant couples, where men's involvement in testing may enable the couple to address condom use, decrease sex with outside partners and anti-retroviral adherence if HIV positive to prevent HIV and other sexually transmitted infections transmissi on to the uninfected partner and fetus (Sapkota et al., 2011) 
Informational support from care providers involves the provision of counseling, advice, suggestions, and information that the couple can use to address social cultural problems (Nsreen, 2012). This includes health promotion using health messages, explaining laboratory results radiological outcomes and findings of physical examination by a skilled care provider with the aims of raising knowledge about obstetric conditions that traditional healers traditional birth attendants or religion do not know or solve. It includes information on early detection and treatment of problems such as Pre-eclampsia, tuberculosis, malaria, diabetes control, prevention of complications like maternal and neonatal tetanus, anaemia, information on emergency readiness and birth preparedness (Redshaw 2013). Vermeulen et al., (2016), asserts that mmotivational talks on male partner involvement in ANC promote interest in men to participate in maternal care, alleviate cultural believes, social undermining and expression of negative criticisms to the male partner from other men or neighborhoods where men who give social support to pregnant partners are subjected to mockery (Roth et al., 2010).

Appraisal support involves the provision of constructive feedback that is useful for selfevaluation concerning taking required self- determined steps towards health, and essential elements on the side of the male partner to prevent maternal deaths by assisting in seeking recommended antenatal visits, skilled care attendance with emergency backup such as doctors, nurses and midwives who have the skills and knowledge to recognize the onset of complications, emergency obstetric causes of maternal neonatal deaths and postnatal care. This support encourages male partner to understand dire paternal involvement to maternal health which are missed when men fail to accompany partners to antenatal clinic appointments.

Instrumental support involves the provision of tangible services from the male partner or care givers that directly assist the pregnant woman. Male involvement in ANC leads to supporting the spouse financially and enables utilization of ANC services and early male partner decision making thus a reduction in the first two phases of delays thereby altering maternal health positively. Care giver provides instrumental support from a facility by providing necessary antenatal health care, timely meeting needed emergency care, protection from injury or further health danger and prevention and treatment of infections.

Emotional support during pregnancy is associated with sharing paternal social relationship, encouraging the female partner to seek antenatal care, provision of company and helping her keep her appointments. It also includes showing love, empathy, trust, caring, unconditioned acceptance, eating and sleeping together with the male partner aids in relieving anxiety.

\subsection{Empirical review}

Aluisio, (2011) found male involvement in antenatal care is a problem identified by different researchers and experienced globally. Researchers have found that male partners' involvement in antenatal health services is a major milestone to reducing maternal morbidity and mortality by ensuring women receives needed male partner support throughout pregnancy. Accordingly, every pregnancy situation requires male partner involvement which is critical if improvement and reduction of maternal morbidity and mortality is to be realized (Kakaire et al., 2011).

Although studies have documented a number of socio-cultural barriers to male partner involvement in maternal health very little information is known about the social cultural practices that characterizes male partner involvement in maternal health among policemen. According to Byamugisha, et al. (2010), there are different factors which have been identified as barriers to male involvement in the ANC among them Socio Cultural factors. In Gambia, for instance, the National Reproductive Health Policy (2007/2014), was aimed at addressing 
the low level of male participation in reproductive and child health services. However, despite this significant stride, there is minimal support from men. Other proximal determinants include traditional perceptions associated with pregnancy where majority of male participants reported that they are usually not aware of their wives' pregnancy until late stage, indicating lack of communication between husband and wife (Lowe M,2016).

Male partners' participation is restricted by cultural practices like reliance on traditional birth attendants for pregnancy care. According to interviews, men who escorts a pregnant woman to ANC may be subjected to neighbourhood Social stigma (Singh D,2014) Studies shows that Mozambique has the lowest ANC service uptake despite availability of free maternal services which is attributed to beliefs that uptake of such services, particularly, if supported by a male partner, reflects a woman's HIV-positive status (Matiang'i et al., 2013). Study done at Kwale County showed that men give financial support to partners during maternity periods. However, emotional and physical support like attending ANC together is low which is shaped by cultural and gender roles Onyango et al., (2010)

Pathfinder International (N.D) findings reveal that men have capitalized on religion injunction to subjugate women on reproductive health issues where some religious Leaders and adherents asserts that prayer is enough to protect members from contracting HIV/AIDS, pregnancy complication or sexually transmitted infections. Available number of male partners in most facilities accompanying wives are based on PMTCT but is still low (Theurin et sl., 2009). In order to improve men's participation, reasons for poor or reluctances in involvement needs to be explored (Vermeulen et al., 2016)

\subsection{Justification of the study}

Male partner involvement in antenatal care is a crucial component in the optimization of maternal health and achievement of the third Universal Sustainable Development Goal. What influences male partners involvement in ANC at ASTU was established. The findings have availed evidence base for care interventions to enhance importance of accompanying pregnant partners to Uncoffining's yielded evidence base to the Kenya Government, Non-Governmental Organizations and Policy makers for planning for the police officers' involvement in antenatal care. Results yielded literature for future researchers. The study findings add and support other studies on the topic.

\subsection{METHODOLOGY}

\subsection{Study Setting, Design and population.}

Setting: The study was carried out on men aged between twenty and sixty years working at Anti-Stock-Theft-Unit of Gilgil ward in Nakuru County.

Study Design: Descriptive cross-sectional study design was adopted and data collection from the sampled population was done at one point in time under natural setting.

Population: The population for the study was 2582. This population was selected because of its urban and rural characteristics as well as its rich diverse and more proportionate ethnic distribution which provided the opportunity to involve in the study informants from different ethnic groups. Further this provided broader understanding of the subjects in terms of individual and cultural variations. Therefore, the generated finding has given a feeling of what it would have been obtained in the rural settings. Additionally, literacy rate is higher in this population and health services are reachable. Again, greater Gilgil ward population is formed 
International Journal of Health, Medicine and Nursing Practice ISSN 2710-1150 (Online)

Vol. 3, Issue No.1, pp 1 - 15, 2021

www.carijournals.org

by the armed forces and National Youth Service who have the same characteristics ideal for results generalization.

\subsection{Sample size determination}

Fishers formula was used to calculate the desired sample size which was 334 subjects from a population of 2582 .

\subsection{Inclusion criteria and Exclusion criteria}

\subsubsection{Inclusion criteria}

All male Police officers working at Anti-Stock-Theft-Unit aged between 20 and 60 years from constable to superitendant, married and whose wives were or have been pregnant.

\subsubsection{Exclusion criteria}

Police officers who were not able to participate due to sickness, off duty, or not willing to participate.

\subsection{Sampling method}

Sampling method was simple random sampling procedure.

\subsection{Data collection Instruments}

Data collection tool was a structured self-administered questionnaire which included study requirements for the researcher and the subjects. The consent section was signed by respondents who fell in the inclusion criteria.

\subsubsection{Validity and reliability of data collection tool}

Registered community health nurses from Gilgil Sub-County Hospital were trained as research assistants to ensure quality data collection. Tool validity was ensured by a pre-test to a sample of 30 subjects selected randomly from 330 male subjects from Gilgil Sub-County police Station and reliability was confirmed by a test-retest.

\subsection{Data collection process, analysis and presentation of the findings.}

The subjects who consented were enrolled into the study and data was collected during the morning parade of the interview day. After editing, data was coded, and organized with help of statistical Package for Social Sciences (SPSS) then analysed using descriptive and inferential statistics. Chi square and Fishers exact tests were performed to test the hypothesis and the information presented in tables and percentages. 
International Journal of Health, Medicine and Nursing Practice ISSN 2710-1150 (Online)

Vol. 3, Issue No.1, pp 1 - 15, 2021

www.carijournals.org

\subsection{DATA ANALYSIS AND PRESENTATION}

\subsection{Descriptive analysis}

\subsubsection{Demographic Characteristics}

Table 2, shows lower than half (47.9\%) of the respondents were aged between 20 and 30 years, (26.9\%) were aged between $31-40$ years $(14.7 \%)$ between 41 to 50 years and $(10.5 \%)$ were the minority aged between 51 - 60 years.

Table 2: Respondents age

\begin{tabular}{llll}
\hline Responses & Frequency & \multicolumn{2}{c}{ percentages } \\
\hline 20 - 30 years & 160 & $47.9 \%$ & \\
$31-$ 40 years & 90 & $26.9 \%$ & \\
$41-50$ years. & 49 & $14.7 \%$ & \\
$51-60$ years & 35 & $10.5 \%$ & \\
Total & & & $\mathbf{1 0 0 \%}$ \\
\hline
\end{tabular}

\subsubsection{Respondents number of wives}

Majority (62.9\%) of the respondents had one wife while the rest had more than one representing a $(37.1 \%)$ of respondents being polygamous as shown in table 3.

Table 3: Number of wives

\begin{tabular}{lcc}
\hline Responses & Frequency & Percentages \\
\hline One & 210 & $62.9 \%$ \\
Two & 90 & $26.9 \%$ \\
Three & 24 & $7.2 \%$ \\
More than three & 10 & $3 \%$ \\
Total & $\mathbf{3 3 4}$ & $\mathbf{1 0 0}$ \\
\hline
\end{tabular}

\subsubsection{Number of children}

More than half $(62.6 \%)$ of the subjects had one child while $(37.4 \%)$ had two and above as shown in table 4 below which depicts respondents had pre opportunity to experience the partner's antenatal status thus making them the right subjects for the study.

Table 4: Numbers of Children

\begin{tabular}{lll}
\hline Responses & Frequency & Percentages \\
\hline One & 209 & $62.6 \%$ \\
Two & 25 & $7.5 \%$ \\
Three & 11 & $3.3 \%$ \\
More than three & 89 & $26.6 \%$ \\
Total & $\mathbf{3 3 4}$ & $\mathbf{1 0 0 \%}$ \\
\hline
\end{tabular}


International Journal of Health, Medicine and Nursing Practice ISSN 2710-1150 (Online)

Vol. 3, Issue No.1, pp 1 - 15, 2021

www.carijournals.org

\subsubsection{Religion}

Table 5 shows more than half $(65.9 \%)$ of respondents were affiliated to religion and agreed that religious beliefs impair male partner involvement in antenatal care while $(34.1 \%)$ disagreed with this view.

Table 5: Religion

\begin{tabular}{lll}
\hline Responses & Frequency & Percentages \\
\hline Agree & 220 & $65.90 \%$ \\
Disagree & 114 & $34.10 \%$ \\
Total & $\mathbf{3 3 4}$ & $\mathbf{1 0 0}$ \\
\hline
\end{tabular}

\subsubsection{Preferred care provider}

Table 5 shows that, more than three quarters $(77.2 \%)$ of the participants preferred traditional birth attendants for antenatal care compared to (15.6\%) for care givers. A few ( $6 \%$ ) preferred traditional healers, $(1.2 \%)$ of the respondents indicated preferences for mother-in-law.

Table 6: Preferred care provider

\begin{tabular}{lcc}
\hline Responses & Frequency & Percentages \\
\hline Traditional birth attendants & 258 & $77.2 \%$ \\
Care providers & 52 & $15.6 \%$ \\
Mother in-law & 4 & $1.2 \%$ \\
Traditional Healers & 20 & $6 \%$ \\
Total & $\mathbf{3 3 4}$ & $\mathbf{1 0 0}$ \\
\hline
\end{tabular}

\subsection{Inferential Statistics}

\subsubsection{Relationship between Religion and accompanying partner during first ANC visit}

Table 7 below shows relationship between religion and accompanying partner during first ANC visit. Less than half (42.9\%) of the participants who accompanied the partners to the first ANC indicated that religion impairs male partner involvement in antenatal care while $(17.9 \%)$ disagreed. Of the (39.3\%) participants who did not accompany the partners associated it to their religious beliefs. To test the hypothesis that there is no significant relationship between religion and male partner participating in maternal care, a chi square test of independence was conducted. The p-value for the test was 0.047 which is less than 0.05 hence we reject the null hypothesis and conclude that religion has effects on the male participating in ANC. 
International Journal of Health, Medicine and Nursing Practice ISSN 2710-1150 (Online)

Vol. 3, Issue No.1, pp 1 - 15, 2021

WwW.carijournals.org

Table 7: Relationship between religion and accompanying partner during first ANC visit

\begin{tabular}{|c|c|c|c|c|c|c|c|}
\hline \multirow[t]{2}{*}{ Variable } & & \multicolumn{3}{|c|}{$\begin{array}{l}\text { Religion impairs male partner } \\
\text { involvement in antenatal care }\end{array}$} & \multirow[t]{2}{*}{$\begin{array}{l}\text { Chi- } \\
\text { square } \\
\text { Value }\end{array}$} & \multirow[t]{2}{*}{ DF } & \multirow[t]{2}{*}{ P-value } \\
\hline & & $\begin{array}{l}\text { Agree } \\
\mathbf{N}(\%)\end{array}$ & $\begin{array}{l}\text { Disagree } \\
\mathbf{N}(\%)\end{array}$ & Total & & & \\
\hline $\begin{array}{l}\text { Didyou } \\
\text { accompany } \\
\text { your partner }\end{array}$ & YES & $143(42.9)$ & $60(17.9)$ & 203 & 3.939 & 1 & 0.047 \\
\hline $\begin{array}{lr}\text { during her } \\
\text { first } \\
\text { visit }\end{array}$ & $\mathrm{NO}$ & 131(39.3) & $0(0)$ & 131 & & & \\
\hline
\end{tabular}

4.2.2 Relationship between preferred care provider and accompanying partner to ANC

Most (82.3\%) of the subjects who accompanied the pregnant partners to the first ANC preferred health care providers to care for the partners while (11.82\%) preferred traditional birth attendants and (5.9\%) mother-in-law. Of the subjects who did not accompany the partners, (32.1\%) indicated preference for traditional birth attendants and (3.6\%) cited health care givers. To test the hypothesis that there is no significant relationship between preferred care providers and male partner participating in maternal care, a chi square test of independence was conducted. The p-value for the test was 0.001 which is less than 0.05 hence we reject the null hypothesis and conclude that preferred care givers have effects on the male participating in ANC.

Table 8, Relationship between preferred care provider and accompanying partner during first ANC visit.

\begin{tabular}{|c|c|c|c|c|c|c|c|c|}
\hline \multirow[t]{2}{*}{ Variable } & & \multicolumn{4}{|c|}{ Preferred care provider } & \multirow{2}{*}{$\begin{array}{l}\text { Chi- } \\
\text { square } \\
\text { Value }\end{array}$} & \multirow[t]{2}{*}{ DF } & \multirow{2}{*}{$\begin{array}{l}\text { P- } \\
\text { value }\end{array}$} \\
\hline & & $\begin{array}{l}\text { Traditional } \\
\text { birth } \\
\text { attendant } \\
\mathrm{N}(\%)\end{array}$ & $\begin{array}{l}\text { Health } \\
\text { care } \\
\text { provider } \\
\mathrm{N}(\%)\end{array}$ & $\begin{array}{l}\text { Mother } \\
\text { in-law }\end{array}$ & Total & & & \\
\hline \multirow{2}{*}{$\begin{array}{lr}\text { Did } & \text { you } \\
\text { accompany } \\
\text { your partner } \\
\text { during her } \\
\text { first } \\
\text { visit }\end{array}$} & YES & $24(11.82)$ & $167(82.3)$ & $12(5.9)$ & 203 & $15.130^{\mathrm{a}}$ & 2 & 0.001 \\
\hline & NO & $107(32.1)$ & $12(3.6)$ & $\begin{array}{l}12 \\
(3.6)\end{array}$ & 131 & & & \\
\hline
\end{tabular}


International Journal of Health, Medicine and Nursing Practice ISSN 2710-1150 (Online)

Vol. 3, Issue No.1, pp 1 - 15, 2021

WWW.carijournals.org

\subsection{DISCUSSIONS, CONCLUSION AND RECOMMENDATIONS}

\subsection{Discussion of the Findings}

More than a half (65.9\%) of the subjects indicated religion impairs male partner involvement in ANC while 34.1\% disagreed. These results concur with Kululanga et al., (2012) study in Bangladesh, Egypt, and Pakistan which cited religion, as a reason man would not disclose to partners' health issues or participate in ANC and concluded that, religion is a barrier for men to engage in pregnancy matters. In this study all participants who accompanied the partners for the first ANC disagreed that religions impair male partner participation in maternal care while those who did not, agreed that it does. Chi squire test of impendence $(p=0.047)$. More than three quarters $(77.2 \%)$ of the participants preferred traditional birth attendants for care compared to $15.6 \%$ for health care providers. This report agrees with Clement (2016) view of Gambia policy (National Reproductive Health Policy 2007-2014) which stated that in some cultures, only traditional birth attendants attend to antenatal needs. On cross tabulation, majority (93.3\%) of participants who accompanied the partners on the first ANC visit preferred health care workers. Those who did not accompany the partners $(81.8 \%)$ preferred traditional birth attendants. Chi squire test of impendence $(\mathrm{p}=0.001)$.

\subsection{Conclusion}

Male deliberate and active participation is needed to ensure better maternal health. However, the study has revealed that male partners from the study area do not clearly engage in the pregnant partners' prenatal care despite the importance and women are less supported by the partners resulting to low antenatal clinic attendances. It is concluded that the findings are based on individuals' reports and not on close observation of what actually happens in urban or rural settings. Nevertheless, the results hold important implications for policy and or practice and are based on the assumptions that the respondents' responses can be generalized.

The findings established that married males, aged between twenty and sixty years with children and affiliated to religion were the respondents. It is concluded that, lack of security, experience and personal determinants of not wanting the new responsibilities in young male partners, impair participation in prenatal care. Again, in polygamous unions, senior wives are abandoned for younger ones and are not accompanied to antenatal care visits when compared to their counterparts in monogamous marriages.

The study concludes that there is little or no information given to this population to enhance knowledge and understanding of population processes such as current rates of morbidity, mortality and survival among pregnant women and societal change from traditional practices to utilization of skilled and knowledgeable health care personnel and facilities for proper care. Men generally do perceive their principal responsibilities as being providers, decision makers and financiers, where the partner has to cope and use services which are near and cheap. Others strictly adhere to culture and demand consulting with traditional authorities. Additionally, in the first visit the mothers' profile is mandatory which includes male partner accompanying the pregnant woman, testing for Human immune suppressant virus and receiving results. From afore said, it is then concluded that men prefer traditional birth attendants since no tests are done and especially when the man has confidentiality concerns, unaware of status, refusing to be tested, or are in denial about known HIV status. Due to foresaid, the researcher concludes that the population under study has not kept off the belief that reproductive care is a woman's affair and that association with the pregnant woman is unmanly. Hence it is concluded that 
health providers have not intensified health talks in the clinic to sensitize and inform all accordingly.

The researcher therefore concludes that socio-cultural determinants notably religion and traditional birth attendants' reliance affect male participation in the antenatal clinic and concludes by including that better pregnancy period and outcomes have been shown when men are directly involved in maternal health through ANC attendances and pregnancy support and so it is important to find ways of improving the current situation.

\subsection{Recommendations and Contributions to the Study}

\subsubsection{Recommendations}

- Recommend to the commanding officer need for the officers to be attending counselling and health talks for informational support so as to know how to give instrumental, emotional and utilization of appraisal support and use of health facility and professionally skilled care givers.

- Recommend to the care givers provision of enough health information which includes benefits of antenatal activities, identifying pregnancy complications early, easily and importance of quick decision making, emergency readiness, preparedness and utilization of emergency obstetric services and do promotions on male partner involvement in antenatal care in settings like sports events, recreation places and through media

- It is recommended that, care givers start offering services that address men's reproductive health needs such as; evaluation of male sexual needs with the pregnant partner, sexual dysfunction, show self-genital examinations, screening for prostate and testicular cancer, diagnosis and treatment of sexually transmitted infections to encourage involvement.

- Recommendation is made to the County Government, development partners and Policy makers to support and pass laws which oblige men to be responsible for pregnant partners.

- Harmonization of Health care givers and traditional authorities through public meetings is recommended so as to support, reorganize and emphasize importance of male partner involvement in antenatal care with the aim of shifting traditional cultural norms using traditional authorities since they command an obligation and may signal the approval on the part of the male partners whose wives are in the rural setups.

- Further research is recommended to investigate strategies to use to optimize male partners involvement in maternal health in this setting.

\subsubsection{Author contributions}

The author Wanjiku Lucy conceptualised the study, obtained approval, collected data and did analysis. Mutisya Kyalo, Daina Kariuki and Wanjiku Lucy interpreted the data drafted and approved the final manuscript. 
International Journal of Health, Medicine and Nursing Practice ISSN 2710-1150 (Online)

Vol. 3, Issue No.1, pp 1 - 15, 2021

WWW.carijournals.org

\section{REFERENCES}

Abass, K., Sakoalia, P., \& Mensah, C. (2012). Socio-cultural practices and male involvement in reducing maternal mortality in rural Ghana. The case of Savelugu/Nanton District of the Northern Region of Ghana. International Journal of Asian Social Science, 2(11), 2009-2026.

Alsoufi, S. (2020). Selected Antenatal Health Care Parameters of Pregnant Women's in Duhok Province, Iraq. University of Thi-Qar Journal, 15(2), 44-61.

Aluisio, A., Richardson, B. A., Bosire, R., John-Stewart, G., Mbori-Ngacha, D., \& Farquhar, C. (2011). Male antenatal attendance and HIV testing are associated with decreased infant HIV infection and increased HIV free survival. Journal of acquired immune deficiency syndromes (1999), 56(1), 76.

Azuh, D. E., Fayomi, O. O., \& Yartey Ajayi, L. (2015). Socio-cultural factors of gender roles in women's healthcare utilization in Southwest Nigeria. Open Journal of Social Sciences, 3, 105-117.

Byamugisha, R., Åstrøm, A. N., Ndeezi, G., Karamagi, C. A., Tylleskär, T., \& Tumwine, J. K. (2011). Male partner antenatal attendance and HIV testing in eastern Uganda: a randomized facility-based intervention trial. Journal of the International AIDS Society, 14(1), 43-43.

Clement, S., Sikorski, J., Wilson, J., Das, S., \& Smeeton, N. (1996). Women's satisfaction with traditional and reduced antenatal visit schedules. Midwifery, 12(3), 120-128.

Dhange, P., Breeze, A. C., \& Kean, L. H. (2013). Routine antenatal management at the booking clinic. Obstetrics, Gynaecology \& Reproductive Medicine, 23(2), 45-52.

Durban, J. (2014). Despair and hope: on some varieties of countertransference and enactment in the psychoanalysis of ASD (autistic spectrum disorder) children. Journal of Child Psychotherapy, 40(2), 187-200.

Essendi, H., Mills, S., \& Fotso, J. C. (2011). Barriers to formal emergency obstetric care services' utilization. Journal of Urban Health, 88(2), 356-369.

Kakaire, O., Kaye, D. K., \& Osinde, M. O. (2011). Male involvement in birth preparedness and complication readiness for emergency obstetric referrals in rural Uganda. Reproductive health, 8(1), 1-7.

Kato-Wallace, J., Barker, G., Eads, M., \& Levtov, R. (2014). Global pathways to men's caregiving: Mixed methods findings from the International Men and Gender Equality Survey and the Men Who Care study. Global Public Health, 9(6), 706-722.

Kululanga, L. I., Sundby, J., Chirwa, E., Malata, A., \& Maluwa, A. (2012). Barriers to husbands' involvement in maternal health care in a rural setting in Malawi: a qualitative study. J Res Nurs Midwifery, 1(1), 1-10.

Matiang'i, M., Mojola, A., \& Githae, M. (2013). Male involvement in antenatal care redefined: a cross-sectional survey of married men in Lang'ata district, Kenya. African Journal of Midwifery and Women's Health, 7(3), 117-122. 
Namasivayam, A., Osuorah, D. C., Syed, R., \& Antai, D. (2012). The role of gender inequities in women's access to reproductive health care: a population-level study of Namibia, Kenya, Nepal, and India. International journal of women's health, 4, 351.

Nwakwuo, G. C., \& Oshonwoh, F. E. (2013). Assessment of the level of male involvement in safe motherhood in Southern Nigeria. Journal of community health, 38(2), 349-356.

Onyango, M. A., Owoko, S., \& Oguttu, M. (2010). Factors that influence male involvement in sexual and reproductive health in western Kenya: a qualitative study. African journal of reproductive health, 14(4).

Roth, D. M., \& Mbizvo, M. T. (2001). Promoting safe motherhood in the community: the case for strategies that include men. African journal of reproductive health, 5(2), 10-21..

Straughen, J. K., Caldwell, C. H., Young, A. A., \& Misra, D. P. (2013). Partner support in a cohort of African American families and its influence on pregnancy outcomes and prenatal health behaviors. BMC pregnancy and childbirth, 13(1), 1-9.

United Nations (2015). Universal sustainable development Agenda, 3 third goal, September 2015

United States Agency for International Development. (2010). Men Key to Reducing Maternal Deaths in Developing Countries. Front Lines, May. Available at http: // transition. usaid government press/front Lines/fl; May 2010;10/p 08_men100517.html. 